\title{
Presenile dementia syndromes: an update on taxonomy and diagnosis
}

\section{D Greicius, M D Geschwind, B L Miller}

J Neurol Neurosurg Psychiatry 2002;72:691-700

The four major degenerative dementias that often begin in presenescence: are reviewed. These are Alzheimer's disease, frontotemporal dementia, dementia with Lewy bodies, and Creutzfeldt-Jakob disease. Their epidemiological, genetic, and clinical features are reviewed, and controversies in taxonomy arising from recent discoveries described. Particular attention is given to the pathological role of protein aggregation, which appears to be a factor in each disease.

See end of article for authors' affiliations

Correspondence to Professor B L Miller,

Memory and Aging Center University of California San Francisco, Box 1207, 350

Parnassus Avenue, CA 94117, USA;

bmiller@memory.ucsf.edu

Received 22 May 2001

In revised form

6 December 2001

Accepted

18 December 2001
$\mathrm{N}$ ew clinical, pathological, and basic science discoveries often extend, challenge, and eventually change the nomenclature of major medical disorders. Nearly 40 years ago in Newcastle, England, the finding of a strong correlation between dementia in elderly nursing home patients and $\beta$ amyloid plaque concentration in the brain transformed our understanding of what constituted Alzheimer's disease. ${ }^{1}$ Before this key series of studies, Alzheimer's disease was considered a rare disorder that afflicted presenile populations, while dementia in the elderly, or "senility", was a poorly defined condition thought to be secondary to cerebral arteriosclerosis. Linking the brain changes originally described by Alzheimer in patients with a presenile dementia to patients with senile dementia transformed the field. Subsequent studies on the genetic basis, pathogenesis, and clinical sequelae of the amyloid plaque have produced a remarkably coherent picture of Alzheimer's disease across all these areas of research. The same has been true for the varied set of genetic, infectious, and sporadic disorders that were linked together through the discovery of prions. ${ }^{2}$

In contrast, nomenclature issues with what was once called Pick's disease ${ }^{3}$ and is now called frontotemporal dementia ${ }^{4}$ have been more complicated, and recent discoveries challenge previous dogma regarding how we should classify patients with the widely varied clinical and pathological syndromes now linked to frontotemporal dementia. Dementia with Lewy bodies (DLB) also presents a less coherent picture, given its predominantly non-Mendelian genetics and considerable overlap with both Alzheimer's disease and Parkinson's disease.

Increasingly, neurodegenerative syndromes are considered disorders of abnormal protein aggregation-a concept discussed in an accompanying article in this issue of the journal. Alzheimer's disease is strongly linked to the accumulation of amyloid $\beta-42$ protein $(A \beta 42),{ }^{5}$ frontotemporal dementia to abnormalities in the protein tau,$^{6-8}$ DLB to abnormal aggregation of the $\alpha$ synuclein protein, ${ }^{9}$ and Creutzfeldt-Jakob disease to abnormal aggregation of prions. ${ }^{2}$ With each of these dementias there are genetically determined forms of the illness caused by mutations in genes that either code for or affect the function of a protein. Similarly, for each dementia subtype there is a sporadic form of the illness in which no genetic abnormalities are evident. Beyond the single gene mutations that lead to abnormal protein aggregation there are susceptibility genes that increase the likelihood that abnormal protein aggregation will occur. An apolipoprotein gene, $\epsilon 4$, represents a susceptibility gene for Alzheimer's disease and $\mathrm{DLB}^{10-12}$ while homozygosity for codon 129 on the prion protein increases susceptibility to CreutzfeldtJakob disease (table 1).

The remarkable coherence between clinical, pathological, and molecular findings in both Alzheimer's disease and Creutzfeldt-Jakob disease has protected these disorders from major controversy over nomenclature. However, with frontotemporal dementia the field is substantially divided between "lumpers" and "splitters". This dispute is complicated by the discovery of substantial overlap between frontotemporal dementia and disorders traditionally considered under the category of parkinsonian-dementia syndromes, including progressive supranuclear palsy and corticobasal ganglionic degeneration. ${ }^{14}{ }^{15}$ Similarly, DLB has been subject

\begin{tabular}{|c|c|c|c|c|}
\hline Type & Abnormal protein & $\begin{array}{l}\text { Predisposing genetic } \\
\text { mutations }\end{array}$ & Susceptibility genes & $\begin{array}{l}\text { Per cent of predisposition } \\
\text { mutations }\end{array}$ \\
\hline Alzheimer & Amyloid $\beta-42$ & $\begin{array}{l}\text { Amyloid precursor protein, } \\
\text { presenilin 1, presenilin } 2\end{array}$ & Apolipoprotein E4 & $<5 \%$ \\
\hline Frontotemporal dementia & Tau & Tau introns and exons & Unknown & $<10 \%$ \\
\hline Dementia with Lewy bodies & $\alpha$ Synuclein & $\alpha$ Synuclein, $4 p$ locus & Apolipoprotein E4 & $<1 \%$ \\
\hline Creutzfeldt-Jakob & Prion & Prion protein & Prion protein codon 129 & $<15 \%$ \\
\hline
\end{tabular}


to nomenclature controversy owing both to the prominent clinical overlap with Alzheimer's disease and Parkinson's disease and to inconsistent clinical criteria. In this article we review the four major degenerative dementias that often begin in presenescence: Alzheimer's disease, frontotemporal dementia, DLB, and Creutzfeldt-Jakob disease. We review some epidemiological, genetic, and clinical features of these disorders and describe controversies in taxonomy that have arisen from recent discoveries.

\section{ALZHEIMER'S DISEASE}

Alzheimer's disease is the most common degenerative dementia, accounting for around two thirds of all cases. ${ }^{16}$ Alzheimer's disease most commonly occurs in late life, but a small percentage of patients have onset before 60 years (presenile). Differences between early and late onset cases do exist, and one clear distinction is that many presenile cases are secondary to known genetic mutations. In contrast, the aetiology of late life Alzheimer's disease is more heterogeneous, with many factors-genetic, age related, and environmentalcontributing to the dementia. Despite these and other differences between presenile and senile Alzheimer's disease, most consider the two to be the same illness. Even though only a small minority of Alzheimer patients show dementia in the presenium, these relatively uncommon presenile cases have had a great impact upon our understanding of the pathogenesis of the disease.

In around $2 \%$ of cases, ${ }^{17}$ Alzheimer's disease is transmitted as an autosomal dominant gene with strong penetrance. Most of these autosomal dominant cases present before the age of 60 . Three genes account for these familial cases, and all three result in excessive production of $\beta$ amyloid 42 (A $\beta 42$ ), the most neurotoxic of the three common forms of amyloid. The original studies on familial Alzheimer's disease focused on chromosome 21 because the amyloid precursor protein is located on this chromosome and because all patients with Down's syndrome (trisomy 21) develop amyloid plaques by the age of $40 .^{18}$ The amyloid precursor protein gene on chromosome 21 was the first Alzheimer's disease related gene to be identified and characterised, ${ }^{19} 20$ and new mutations in the gene continue to be identified. Most of the early onset cases with a documented genetic basis are caused by mutations of the presenilin 1 gene found on chromosome 14, and most of these cases occur before the age of $50 .{ }^{21}$ However, there are a few cases caused by mutations in a homologous gene called presenilin 2 on chromosome $1 .{ }^{22}$ Presenilin genes code for a pair of proteins that share considerable biochemical overlap, which, when mutated, favour the production of $\mathrm{A} \beta 42 .{ }^{23} \mathrm{~A}$ fourth gene, apolipoprotein $\epsilon$, coding for apolipoprotein $\mathrm{E}$ (apoE), has been implicated in the more common late onset, sporadic form of Alzheimer's disease. ApoE has three common alleles-E2, E3, and E4-and it is the E4 allele that increases susceptibility to Alzheimer's disease. ${ }^{10}{ }^{24}$ The apoE4 allele is neither necessary nor sufficient for the development of Alzheimer's disease. However, the majority of cases of Alzheimer's disease between the ages of 50 and 60 years are homozygous or heterozygous for apoE4. ${ }^{10}$ Other potential susceptibility genes have been proposed..$^{25}$

It is not possible to differentiate presenile from senile Alzheimer's disease on the basis of neuropathological findings. Alzheimer's disease has three important pathological findings: amyloid plaques, neurofibrillary tangles, and neuronal loss. The mechanisms through which plaques, tangles, and neuronal loss develop can be traced by studying genetic forms of the disease and by evaluating mice carrying genetic mutations. Amyloid plaques are extraneuronal aggregates of $A \beta$ protein. Neurofibrillary tangles are aggregations of tau and neurofilaments found in neuronal cell bodies. The plaques and tangles lead to neuronal loss. One staging system for Alzheimer's disease emphasises the density of neurofibrillary tangles. ${ }^{26}$ This system relies upon the fact that neurofibrillary tangle distribution and density are the best correlates of cognition $^{27}$; it stages disease severity from I to VI, with stages I and II confined to the entorhinal and hippocampal cortex, and stages $\mathrm{V}$ and VI involving the neocortex.

A consensus on the clinical diagnosis of Alzheimer's disease was reached in 1984 with the development of the NINCDSADRDA criteria. ${ }^{28}$ These criteria remain valid today. To meet the diagnostic criteria for probable Alzheimer's disease, a patient must have deficits in at least two areas of cognition, progressive worsening of memory and other cognitive functions, and onset between ages 40 and 90. Many individuals who carry presenilin 1 mutations become ill before age 40 , diminishing the value of this item in the criteria. The criteria require there to be no other neurological disorder that could explain the cognitive decline, and therefore the clinician must be able to differentiate Alzheimer's disease from frontotemporal dementia, DLB, Creutzfeldt-Jakob disease, or other causes of dementia. The NINCDS-ADRDA criteria do not offer much guidance for differentiating other dementias from Alzheimer's disease. Therefore they show good sensitivity (90-95\%) but only modest specificity $(60-70 \%) \cdot{ }^{29-31}$ Efforts have been made to increase the specificity by using adjunctive investigations such as blood tests, cerebrospinal fluid analysis of $\mathrm{A} \beta 42$, and measurements of apoE status, yet none of these tests has reached the level of a gold standard for diagnosis. ${ }^{32}{ }^{33}$

In the first stages of Alzheimer's disease, when it is pathologically confined to the medial temporal region, patients have episodic memory deficits. Forgetfulness, difficulty in learning new spatial routes, problems with remembering where items have been placed, and difficulty in remembering new names or faces are common symptoms. As the disease moves from the medial temporal lobe to the posterior temporoparietal cortex, language and visuospatial deficits emerge. A thorough mental state examination can therefore often provide a rough estimate of the pathological stage of disease, such that isolated memory impairment may correlate with stage II or III, whereas memory impairment coupled with prominent visuospatial or language difficulties suggests progression to stages $\mathrm{V}$ or VI. In studies of patients carrying the genetic mutations that predispose to Alzheimer's disease, a decline in verbal memory and performance intelligence quotient seem to be the earliest manifestations of the illness. ${ }^{34}$

Focal variants of Alzheimer's disease are seen, where memory loss is not a prominent early feature. These focal presentations are common in the presenile setting. In such cases, isolated cognitive impairments occur based upon focal cortical brain degeneration. Naming, praxis, and calculation deficits are seen with focal degeneration in the left temporoparietal regions, ${ }^{35}$ loss of executive function and behaviour deficits with focal degeneration in the frontal lobes, ${ }^{36}$ visuospatial loss develops with asymmetric right parietal degeneration, and visual disturbances emerge with posterior cortical degeneration. ${ }^{37}$ In these cases, Alzheimer's disease may mimic other focal degenerative disorders such as frontotemporal dementia presenting with primary progressive aphasia, or corticobasal degeneration presenting with progressive apraxia. ${ }^{38}$ Psychiatric symptoms are common with Alzheimer's disease, particularly as the illness progresses. In addition to relatively mild behavioural problems such as irritability and sleep disturbance, major depression occurs in up to $20 \%$ of patients and in the later stages up to $50 \%$ will have delusions. ${ }^{39}$ Alzheimer's disease is slowly progressive but ultimately fatal. Median survival following the onset of symptoms has been estimated to be in the range of five to nine years. ${ }^{40}{ }^{41}$ In presenile dementia the course is sometimes more rapid.

The diagnostic value of neuroimaging is now under active study. Positron emission tomography (PET) and single photon emission tomography (SPECT) have been used as adjunctive tests in patients with probable Alzheimer's disease, with the 
fairly consistent finding of decreased perfusion or metabolism in the temporoparietal regions..$^{352}$ Measures of hippocampal and entorhinal cortex atrophy with structural magnetic resonance imaging (MRI) have been used in efforts to increase diagnostic accuracy. ${ }^{43}{ }^{44}$ Studies of functional imaging using MRI or PET are still relatively sparse but suggest a pattern of increased task-related activation in the earliest clinical and perhaps even preclinical state, progressing to decreased task-related activation once patients become more symptomatic. ${ }^{45}$ With the prospect of preventive interventions for Alzheimer's disease, enhanced understanding of genetic risks, and growing awareness that many patients with minimal cognitive impairment progress to Alzheimer's disease,${ }^{47}$ techniques are being investigated that increase diagnostic specificity in demented and at risk individuals. To date, neuroimaging has been able to distinguish group differences but still lacks specificity for Alzheimer's disease at the individual patient level.

Treatment options for Alzheimer's disease, while still modest in their effect, have continued to emerge and there are now treatments to improve or maintain cognition, prolong independence in activities of daily living, and minimise behavioural problems. The mainstay of treatment currently involves the use of an acetylcholinesterase inhibitor. Several different inhibitors are available with similar efficacy but varying half lives and side effect profiles. ${ }^{48}$ Studies suggest that the efficacy of these compounds is modest but can persist for years with continued treatment. ${ }^{49-51}$ Vitamin E has shown efficacy in slowing progression of Alzheimer's disease and has no important side effects. ${ }^{52}$ There are many agents that show promise as treatments to prevent Alzheimer's disease, but none has yet been proven to be effective. In selected patients antidepressants or atypical antipsychotic compounds may improve behaviour, ${ }^{53}{ }^{54}$ though one report has suggested that antipsychotic agents may hasten cognitive decline. ${ }^{55}$

One advance in the study of Alzheimer's disease has been the emergence of transgenic mouse models. Mice carrying mutations in the amyloid precursor protein gene or presenilin 1 gene develop amyloid plaques by six months of age. Various treatments have proven effective in these mice, including lowering cholesterol, ${ }^{56}$ treating with inhibitors of the protease $\gamma$-secretase, ${ }^{57}$ and-perhaps most promisingly-immunising against A $\beta 42 .^{58}$ ApoE4 mice also develop cognitive impairment by six months when compared with mice with wild type apoE or apoE3. ${ }^{59}$ These mice represent a powerful model for studying the mechanisms leading to brain degeneration associated with apoE4 and provide a testing ground for potential treatments.

\section{FRONTOTEMPORAL DEMENTIA}

The nomenclature for frontotemporal dementia has been a modern quagmire, imposed in part by evolving clinical and genetic data. ${ }^{60}{ }^{61}$ This process began with better clinical and pathological studies of patients with frontotemporal dementia by European investigators, ${ }^{62}{ }^{63}$ but was further transformed by the finding of tau mutations in familial forms of frontotemporal dementia. ${ }^{78^{64}}$ No degenerative dementia has seen more names for the same disorder than frontotemporal dementia, which has been called Pick's disease, progressive subcortical gliosis, dementia of the frontal type, frontal lobe dementia of the non-Alzheimer's disease type, thalamic dementia, dementia, disinhibition amyotrophy syndrome, frontotemporal dementia with parkinsonism linked to chromosome 17, multisystem tauopathy, dementia lacking distinctive histology, frontotemporal dementia, and frontotemporal lobar degeneration. ${ }^{65}$

First described by Pick in 1892, and later called Pick's disease in 1924, much has been made of whether the Pick body constitutes a core feature of this illness. ${ }^{3}$ Even though Pick himself had little interest in the cellular inclusions that bear his name, for many decades pathologists were reluctant to make a specific diagnosis in patients with frontal and temporal atrophy unless these cellular inclusions were present. The majority of patients with frontotemporal atrophy do not have cellular inclusions. Therefore, by insisting upon the presence of Pick bodies and by ignoring frontotemporal cases without Pick bodies, the disease originally described by Pick became rare.

With the emergence of Alzheimer's disease as a major research focus during the 1980s, Pick's disease and other related disorders were badly neglected, particularly in the USA. However, a series of studies by the Lund and Manchester groups brought frontotemporal dementia back into the mainstream of dementia research. ${ }^{62}{ }^{63}$ In consecutive patients with progressive dementia, these groups showed that somewhere between $12 \%$ and $16 \%$ of patients with degenerative dementia suffered from a non-Alzheimer's disease pathology characterised by frontotemporal atrophy, neuronal loss, gliosis, and sometimes Pick bodies. A series of studies by these investigators on patients with presenile dementia suggested that frontotemporal dementia was a common presenile illness that could be differentiated from Alzheimer's disease. On the basis of clinical, pathological, and imaging studies, these groups estimated that $12-25 \%$ of presenile dementias could be characterised by frontal lobe atrophy without Alzheimer's disease pathology. ${ }^{62}{ }^{63} 6{ }^{66}{ }^{67}$ Fewer than $20 \%$ of these cases showed the classical pathological findings of Pick's disease, thus giving rise to a large definition-based increase in prevalence.

The Lund-Manchester groups coined the term frontotemporal dementia in 1994 in an attempt to establish reliable diagnostic criteria for a clinically heterogeneous group of disorders that still shared many distinct pathological features. ${ }^{4}$ Recently, a consensus group delineated three main cognitive subtypes of frontotemporal dementia (described in detail below). ${ }^{68}$ The validity of this more inclusive perspective (and, in turn, of those early prevalence estimates) has been borne out by recent advances in molecular genetics.

While frontotemporal dementia was known for many years to have a strong genetic component, the first major stride took place in 1994 with linkage of a familial frontotemporal dementia syndrome to chromosome $17 .{ }^{69}$ Subsequently, mutations in the tau gene on chromosome 17 were identified in clinically distinct frontotemporal dementia kindreds. ${ }^{70}$ Around $40 \%$ of cases of frontotemporal dementia are familial and many of these familial cases seem to be inherited in an autosomal dominant pattern. ${ }^{71}$ Most cases of frontotemporal dementia linked to chromosome 17 have been associated with a specific mutation on the tau gene and abnormal accumulations of tau in the brain. ${ }^{73}$ Recently, it has been discovered that in one of these families an absence of brain tau was a characteristic feature, so called "no tau tauopathy." ${ }^{74}$ Evidence from some familial and sporadic cases suggests that a subgroup of patients with frontotemporal dementia either overexpress or underexpress a subtype of tau, or express a mutated form of tau. However, there are other kindreds with linkage to chromosome 17 that have yet to yield specific mutations in the tau gene. Furthermore, tau mutations do not account for the majority of familial cases and are rarely seen in sporadic frontotemporal dementia. ${ }^{75}$ One report has described a family with frontotemporal dementia linked to chromosome $3 .^{77}$ Families with frontotemporal dementia and a strong association with amyotrophic lateral sclerosis rarely show tau mutations and often have no evidence of tau pathology in the brain. Families have recently been linked to chromosomes $9^{78}$ and 15 (Wilhelmsen KC, personal communication).

Pathologically there is a distinctive focal atrophy of the frontal lobes, the temporal lobes, or both. The atrophy can show a unilateral predominance or be symmetrical. In the temporal lobes the more anterior regions typically show greater pathology, with the amygdala demonstrating more involvement than the hippocampus. ${ }^{4}$ Posterior parietal and 
temporo-occipital regions are relatively preserved. On microscopy, subcortical structures such as the substantia nigra, putamen, and globus pallidus may show marked involvement. Those cases with a motor neurone component also show pathological changes in the anterior horn cells. The microscopic changes in the affected regions include neuronal loss, synaptic loss, gliosis, and spongiosis, often most prominent in the first three cortical layers. ${ }^{79}$ Some cases of frontotemporal dementia show swollen neurones with inclusion bodies. Even among cases with inclusions, only a minority shows the classical histological feature of a Pick body-silver staining. Silver staining appears to be associated with the deposition of 3Rtau rather than the $4 \mathrm{R}$ isoform. ${ }^{80}{ }^{81}$ Families with frontotemporal dementia have been described where neuronal inclusions are tau negative but glial inclusions are tau positive. ${ }^{82}$

Two other disorders-progressive supranuclear palsy and corticobasal degeneration-show substantial clinical and pathological overlap with frontotemporal dementia. ${ }^{83}$ Many patients with progressive supranuclear palsy show frontal/ executive clinical deficits, and apathy is a prominent feature of this disorder. ${ }^{84} 85$ Similarly, corticobasal degeneration often involves the frontal lobes, and frontal presentations of corticobasal degeneration are common. ${ }^{86} 87$ In patients with progressive degeneration of the left peri-insular region who present with primary progressive aphasia, corticobasal ganglionic degeneration pathology has been reported. ${ }^{83}$ Patients with both corticobasal degeneration and progressive supranuclear palsy are more likely to carry the A0 tau allele, and brain pathology in these conditions always shows tau abnormalities ${ }^{88-90}$ The presence of tau positive inclusions in progressive supranuclear palsy and corticobasal degeneration has prompted some to view progressive supranuclear palsy, corticobasal degeneration, and frontotemporal dementia simply as clinical variants of "tauopathy". ${ }^{91}$

The modal age of onset for frontotemporal dementia is in the sixth decade, but diagnosis can be delayed for many years because of the insidious course and the early predominance of behavioural symptoms. ${ }^{65}$ The clinical presentation of frontotemporal dementia varies depending on the focal onset of pathology, and has been divided into three cognitive subtypes: frontal variant, progressive non-fluent aphasia, and semantic dementia. In frontal variant frontotemporal dementia, patients have selective bifrontal or right frontotemporal involvement, and behavioural changes predominate; disinhibition, apathy, lack of insight, lack of empathy, blunted affect, disregard of personal space, decreased grooming, hyperorality, perseverative behaviours, and social inappropriateness are common. ${ }^{92-94}$ In patients with predominantly left hemisphere involvement, progressive language deficits predominate. If this left hemisphere involvement is predominantly frontal, patients show expressive language dysfunction with effortful speech, word finding difficulty, and grammatical errors, but with preserved comprehension (progressive non-fluent aphasia). ${ }^{95-97}$ If the left anterior temporal lobe is predominantly involved, patients may develop progressive loss of knowledge of words and objects (semantic dementia). These clinical distinctions are most apparent earlier in the course and may blur later, as many patients ultimately progress to show more global impairment in frontal and temporal lobe functions. Patients with frontotemporal dementia and language impairment may initially resemble those with focal variant Alzheimer's disease, to the point that one could argue that focal variant Alzheimer's disease is one cause of a clinical syndrome of frontotemporal dementia. ${ }^{35}$ Eventually, however, such accompanying symptoms as hyperorality in frontotemporal dementia and amnesia in Alzheimer's disease should allow antemortem clinical distinction between the two conditions. ${ }^{38}$ Finally, in addition to the various cortical symptoms, some patients with frontotemporal dementia will develop parkinsonian features or symptoms of motor neurone disease. $^{78} 80$
Estimates of life span following a diagnosis of frontotemporal dementia can vary considerably, ranging from three to 15 years, depending on which symptoms are considered to herald the onset of disease..$^{98}$ It is possible that patients with progressive language disorder are more likely to get an early diagnosis than those who present with psychiatric symptoms. Additionally, some of this variability related to the speed of progression is explained by whether or not the patients develop motor neurone disease or parkinsonian features either early or late in the course of the illness.

Given the pronounced variation in initial presentation and the common early prominence of behavioural symptoms, misdiagnosis is a common problem for patients and their families. Clinical criteria alone can be useful in distinguishing frontotemporal dementia from Alzheimer's disease. ${ }^{99}$ In a recent study, the Lund-Manchester criteria were applied retrospectively to a group of pathologically confirmed cases of Alzheimer's disease, frontotemporal dementia, progressive supranuclear palsy, and DLB and found to have a sensitivity of $97 \%$ and a specificity of $97 \% .{ }^{100}$ The criteria have not yet been tested in a prospective manner against pathological diagnoses, but will probably prove to be less sensitive and specific in this setting. Increasingly, therefore, neuroimaging is being relied upon to improve both the sensitivity and the specificity of the diagnosis. The addition of SPECT to clinical criteria has been shown to improve diagnostic accuracy to $90 \%$. Patients with frontotemporal dementia tend to show bifrontal and bitemporal hypoperfusion, in contrast to Alzheimer's disease where there are temporoparietal defects. ${ }^{65}$ More recently, structural MRI has shown promise as an adjunct to help in distinguishing frontotemporal dementia from Alzheimer's disease and other dementias. ${ }^{101}$ For the time being, however, clinical criteria remain the mainstay of diagnosis.

Treatment of frontotemporal dementia is limited to symptom management. Serotonin selective reuptake inhibitors may be beneficial in managing the disinhibition, depressive symptoms, carbohydrate craving, or compulsions often encountered in this disease. ${ }^{102}$ Support for such an approach can be found in molecular studies showing low serotonin receptor binding in frontotemporal dementia. ${ }^{103}$ Some behavioural symptoms may require more aggressive pharmacotherapy, including the use of antipsychotic agents, in which case-as with Alzheimer's disease - the newer atypical agents are favoured in order to minimise parkinsonian side effects. At least one study has suggested that the cholinergic system is relatively spared in frontotemporal dementia, ${ }^{104}$ and often acetylcholinesterase inhibitors do not appear to improve cognitive status and can worsen irritability. ${ }^{105}$

\section{DEMENTIA WITH LEWY BODIES}

As with frontotemporal dementia, the epidemiology of DLB is difficult to establish owing to the variability in the diagnostic criteria. The first case description of DLB is attributed to Okazaki et al in 1961, but standardised, consensus, diagnostic criteria were not established until $1996 .{ }^{106}$ In the interim various different criteria were used to define DLB and so early prevalence estimates must be interpreted with caution. Nonetheless, DLB is increasingly considered to be the second most common degenerative dementia after Alzheimer's disease ${ }^{107}$ and estimates of its prevalence among patients with dementia range as high as $20 \% .{ }^{108}$ Other studies have reported lower estimates, ranging from $8.5 \%$ of dementias in a Scandinavian study ${ }^{109}$ to $15 \%$ in a Japanese study. ${ }^{110}$ Demographically, a male preponderance has been fairly consistently reported, with a ratio of the order of between $1.5: 1$ and $2: 1 .^{111}$

The genetic underpinnings of DLB include an autosomal dominant component linked to familial Parkinson's disease and a non-Mendelian component linked to Alzheimer's disease. Familial cases of Parkinson's disease were initially linked to an autosomal dominant but incompletely penetrant 
mutation in the $\alpha$ synuclein gene on chromosome $4 \mathrm{q} .{ }^{112}$ Soon afterwards, $\alpha$ synuclein was found to be a major component of Lewy bodies. ' Subsequently, two other genetic loci on chromosomes $2 \mathrm{p}$ and $4 \mathrm{p}$ were identified in Parkinson's disease kindreds, also showing autosomal dominant inheritance with incomplete penetrance. ${ }^{113}$ Individuals in one of the kindreds linked to chromosome $4 \mathrm{p}$ have been described who fulfil criteria for DLB rather than Parkinson's disease. ${ }^{114}$ Thus cases of DLB seem to make up only a fraction of the already rare kindreds with familial Parkinson's disease. As with Alzheimer's disease, therefore, the bulk of the genetic load in DLB is non-Mendelian. The more striking similarity is that the susceptibility gene, apoE4, is the same in the two diseases. Several groups have reported increased apoE4 allele frequencies in DLB patients with ${ }^{1115}$ and without ${ }^{12}$ Alzheimer changes. Overall it seems clear that there is an increased frequency of apoE4 in DLB but that the effect is less prominent than in Alzheimer's disease. ${ }^{107}$

The hallmark pathological finding of DLB is, of course, the presence of cortical Lewy bodies. Lewy bodies are intracytoplasmic aggregates of $\alpha$ synuclein and other proteins. ${ }^{9}$ They can be detected on routine haematoxylin and eosin staining, but immunocytochemical stains are more sensitive, $\alpha$ synuclein stains being superior to ubiquitin stains. Some investigators believe that the location and density of Lewy bodies is linked to the clinical syndrome, such that brain stem Lewy bodies correlate with movement disorder, limbic Lewy bodies with psychosis, and cortical Lewy bodies with depression. ${ }^{116}$ Others have not detected a tight correlation between the clinical syndrome and the extent and location of Lewy bodies. ${ }^{117}$

Immunocytochemical stains for ubiquitin and $\alpha$ synuclein have also led to the detection of Lewy neurites, which are abnormal filaments that may be Lewy body precursors. ${ }^{117}$ Because Lewy bodies may be seen in a significant percentage of patients with otherwise typical Alzheimer's disease, the presence of Lewy neurites in CA 2/3 of the hippocampus, more specific for DLB, may be a useful distinguishing neuropathological finding. ${ }^{118}$

Distinguishing features are especially important given the extensive pathological overlap between DLB and Alzheimer's disease. The most recent international workshop report states that $15 \%$ of DLB cases have severe Alzheimer pathology, 55\% have some Alzheimer pathology, and only 30\% have no more Alzheimer pathology than age matched controls. ${ }^{117}$

Insights into the properties of $\alpha$ synuclein are helping to elucidate the pathogenesis of DLB. The normal function of $\alpha$ synuclein remains obscure, though it may play a role in synaptic transport of vesicles or synaptic plasticity. ${ }^{119}$ It is also unclear whether cell injury and death results from loss of the protein's normal function or from a toxic gain of function caused by protein aggregation. Of all the proteins linked to degenerative neurological disorders, $\alpha$ synuclein may have the greatest tendency to aggregate. ${ }^{120}$ As with familial forms of Alzheimer's disease, mutations in $\alpha$ synuclein appear to enhance aggregation of the protein. ${ }^{121}$ Oxidative stress also appears to favour aggregation of $\alpha$ synuclein. ${ }^{122}$ The prominent pathological overlap between Alzheimer's disease and DLB may be linked to $\alpha$ synuclein, given that several laboratories have demonstrated the presence of $\alpha$ synuclein in $\mathrm{A} \beta$ plaques. ${ }^{123}$

Given the ample pathological overlap between Alzheimer's disease and DLB, it is not surprising that the two disorders show prominent clinical overlap as well. The age of onset is usually somewhat younger in DLB but can range from 50 to 83 years. ${ }^{107}$ The consensus criteria established in 1996 begin with the vague category of "progressive cognitive decline" 106 which can involve deficits in attention, visuospatial skills, memory, or less commonly, language. The more specific criteria for DLB include fluctuating cognition, recurrent visual hallucinations, and spontaneous parkinsonism. The presence of at least two of these symptoms qualifies a patient for the diagnosis of probable DLB, while the presence of only one of them suggests possible DLB. The sensitivity and specificity of these criteria were $75 \%$ and $79 \%$ in one retrospective, necropsy confirmed study, ${ }^{124}$ and $22 \%$ and $100 \%$ in another. ${ }^{125}$ Given the poor sensitivity of the criteria, the second international workshop suggested that REM sleep disorder and depression are two additional symptoms of DLB that may increase sensitivity. ${ }^{117}$

Adverse cognitive reactions to antipsychotic agents are felt by some investigators to be a useful clinical feature distinguishing between DLB and Alzheimer's disease. In one retrospective study adverse reactions were found in $81 \%$ of DLB patients and in only $7 \%$ of Alzheimer patients. ${ }^{126}$ The time between diagnosis and death can be quite variable, with studies reporting means of between three and six years but ranging from one to 20 years. ${ }^{107}$ Although two studies ${ }^{127}{ }^{128}$ have shown significant group differences in medial temporal lobe atrophy between Alzheimer's disease (more atrophy) and DLB (less atrophy), the value of structural MRI in individual cases has yet to be shown. Functional neuroimaging techniques with PET or SPECT have not proved to be useful adjuncts to the history and examination. ${ }^{117}$ To date, functional MRI has not been explored as a diagnostic adjunct in DLB. As with Alzheimer's disease and frontotemporal dementia, therefore, the history and clinical examination remain critical in making the diagnosis of DLB.

DLB, like Alzheimer's disease, appears to involve a particularly prominent loss of cholinergic neurones. Several studies have shown that this loss may be even greater than in Alzheimer's disease, ${ }^{107}$ particularly in DLB cases with visual hallucinations. ${ }^{129}$ For this reason, many investigators recommend a trial of a cholinesterase inhibitor in suspected cases of DLB. Improvement in behavioural problems and hallucinations following treatment with acetylcholinesterase inhibitors has been described. ${ }^{130-132}$ One group reported worsening of Parkinsonism as an adverse effect of donepezil in three of nine patients. ${ }^{131}$ While the dopaminergic system also seems to be impaired in DLB, the role of levodopa is less clear. Some patients have shown improvement in extrapyramidal symptoms, while others have shown worsening cognition and hallucinations. Levodopa should probably be reserved for those DLB patients with prominent extrapyramidal symptoms, with special attention to possible adverse cognitive effects.

The use of typical antipsychotics such as haloperidol or chlorpromazine for the treatment of psychosis in DLB is considered risky by many investigators. The use of atypical antipsychotics has also proven to be unpromising, with small case series showing poor tolerance or minimal efficacy of risperidone, ${ }^{133}$ olanzapine, ${ }^{134}$ and clozapine. ${ }^{135}$

\section{PRION DISORDERS}

A family of diseases-the transmissible spongiform encephalopathies (TSE) - are caused by an agent known as the "prion" (proteinaceous infectious particle). Prions (pree-ons) were named and discovered by Stanley Prusiner, who was awarded the 1997 Nobel Prize for this work. ${ }^{136}{ }^{137}$ Prions in animals cause diseases such as bovine spongiform encephalopathy (BSE or mad cow disease) in cattle, scrapie in sheep and goats, and chronic wasting disease of mule deer and elk. ${ }^{138}$ Human prion diseases include Creutzfeldt-Jakob disease, fatal familial insomnia, Gerstmann-Sträussler-Scheinker syndrome, kuru, and new variant Creutzfeldt-Jakob disease (nvCJD or vCJD). Prion diseases can be sporadic, familial, or iatrogenic/ infectious.

Eighty five per cent of prion diseases are sporadic (sCJD), up to $15 \%$ are familial (fCJD, Gerstmann-Sträussler-Scheinker syndrome, fatal familial insomnia), and less than $1 \%$ are iatrogenic. The incidence of Creutzfeldt-Jakob disease is about one per million per year worldwide. ${ }^{137}{ }^{139}$ Iatrogenic cases of Creutzfeldt-Jakob disease have resulted from insufficient decontamination of surgical instruments, corneal transplants, 
dura mater grafts, and human pituitary extract treatment. ${ }^{139}$ Owing to increased awareness, there has been a decline in the iatrogenic transmission of this condition in recent years. ${ }^{140}{ }^{141}$ Familial Creutzfeldt-Jakob disease, Gerstmann-SträusslerScheinker syndrome, and fatal familial insomnia are caused by gene mutations in the prion protein gene. At least 22 mutations have been identified. ${ }^{142}{ }^{143}$ Mutations in the prion protein gene are usually found only in patients from families with clear histories of prion disease, but some mutations seem to be incompletely penetrant and may be found in patients with apparently sporadic illness. ${ }^{144}$

Prions are infectious proteins that are abnormal isoforms of the normal human protein called PrP. Prions reproduce by transforming the normal form of $\operatorname{PrP}\left(\operatorname{PrP}^{\mathrm{C}}\right)$ into the abnormal isoform of prion (scrapie PrP or $\operatorname{PrP}^{\mathrm{sc}}$ ). $\mathrm{PrP}^{\mathrm{sc}}$ has a very different conformation from $\operatorname{PrP}^{c}$. The mechanism of conformational change of $\operatorname{PrP}^{\mathrm{C}}$ to $\mathrm{PrP}^{\mathrm{Sc}}$ is not yet known. ${ }^{144}$ In human prion disease large amounts of $\operatorname{PrP}^{\mathrm{Sc}}$ usually accumulate in the brain. Animal models of infectious prion disease show that neurological dysfunction correlates with levels of $\mathrm{PrP}^{\mathrm{sc}}$ accumulation in the brain. ${ }^{144}$

Both the normal and disease associated PrP isoforms ( $\operatorname{PrP}^{\mathrm{C}}$ and $\operatorname{PrP}^{\mathrm{sc}}$ ) are encoded by Prnp, located on the short arm of chromosome 20. A polymorphism for methionine or valine at codon 129 in Prnp appears to play a significant role in the host susceptibility and phenotypic expression of inherited, iatrogenic, or sporadic Creutzfeldt-Jakob disease. Homozygosity for either methionine or valine at codon 129 results in individuals having a greater susceptibility to developing sporadic or iatrogenic Creutzfeldt-Jakob disease, whereas being heterozygous at this codon seems to be protective. To date, all cases of vCJD have been homozygous for methionine at codon 129, suggesting that methionine homozygosity increases susceptibility to vCJD. ${ }^{144}{ }^{145}$ All familial forms of prion disease are associated with a mutation (point, insertion, and stop codon mutations) in the prion protein gene. The particular mutation can drastically influence the clinical, pathological, and biochemical features of prion disease. ${ }^{143}$

Codon 178 also appears to play a role in phenotypic expression of inherited forms of prion disease. Fatal familial insomnia is seen in persons with the haplotype of an aspartate to asparagine mutation at codon $178(\mathrm{D} 178 \mathrm{~N})$ and a methionine at the polymorphic codon 129. In contrast if codon 129 is valine (and not methionine), the D178N mutation results in a clinical picture typical of Creutzfeldt-Jakob disease rather than fatal familial insomnia. Gerstmann-SträusslerScheinker syndrome is associated both with amino acid substitutions at codons 102, 105, 117, 145, 198, and 217 and with insertional mutations as well in Prnp. ${ }^{143}$

Classically, all prion diseases have a triad of neuropathological features that include vacuolar (spongiform) change, astrogliosis, and neuronal loss. However, each type of human prion disease has its own distinguishing pathological features. Creutzfeldt-Jakob disease is defined pathologically by diffuse vacuolar changes in the grey matter, gliosis, and neuronal loss with few PrP-amyloid plaques. In Gerstmann-SträusslerScheinker syndrome there is much less vacuolar or spongiform change but there are extensive PrP-amyloid plaques; neurofibrillary tangles are found in some forms of this condition. Grossly, there may be mild cerebral or cerebellar atrophy. In fatal familial insomnia, there is neuronal loss and gliosis in the thalamus, inferior olives, and to a lesser extent the cerebellum, but minimal if any vacuolation (spongiform change). vCJD has distinct pathology from the other human prion diseases, with diffuse vacuolation and distinctive, dense core, PrP-containing plaques surrounded by a halo of vacuolar (spongiform) change, called florid plaques. ${ }^{145}{ }^{146}$ In several human forms of prion disease as well as in animal models there is evidence of significant early loss of specific subpopulation of GABAergic, parvalbumin positive, inhibitory interneurones. ${ }^{147-150}$
Though Creutzfeldt is credited with the first description of Creutzfeldt-Jakob disease, his diagnosis has been questioned, as spongiform changes were not found retrospectively in his patient. Jakob described five patients several years later in 1921; of the four in whom the pathology was reviewed retrospectively, only one had spongiform changes. ${ }^{145}{ }^{151}$ Because of this, some people refer to the disease eponymously as JakobCreutzfeldt instead of Creutzfeldt-Jakob disease. ${ }^{152}$

Creutzfeldt-Jakob disease classically presents as a triad of dementia, myoclonus, and ataxia, usually between the ages of 50 and 70 , with a mean age of 60 . The median duration of illness is four months and the mean is 7.6 months. Death occurs within 12 months in $85-90 \%$ of patients. ${ }^{140}$ Creutzfeldt-Jakob disease affects woman and men equally, with an incidence of about one per million. ${ }^{140}{ }^{153-155}$ Patients with Creutzfeldt-Jakob disease usually present with a rapidly progressive dementia, leading to a general decline in overall cognitive function and eventual death. Over the course of the disease, pyramidal and extrapyramidal dysfunction, cerebellar dysfunction, gait, and speech abnormalities can occur. In a minority of patients cortical visual disturbances are present. In approximately one third of patients, vague complaints of fatigue, headache, sleep disturbances, vertigo, malaise, weight loss, poorly defined pain, or behavioural changes may precede the dementia by weeks or months. Also, in about one to two thirds of cases the EEG will eventually show $\mathrm{l}-2 \mathrm{~Hz}$ triphasic periodic sharp waves. ${ }^{140} 144145151$ MR imaging, particularly in sCJD, often shows hyperintensity of the basal ganglia as well as of the cortex on T2, fluid attenuated inversion recovery (FLAIR), and especially on diffusion weighted sequences (DWI). DWI is probably most sensitive for detecting hyperintensity in the affected brain regions, particularly the neocortex, basal ganglia, thalamus, and cerebellum..$^{156-159}$

The most recently recognised form of Creutzfeldt-Jakob disease, occurring primarily in the United Kingdom, has been termed new variant Creutzfeldt-Jakob disease (nvCJD, variant or VCJD) and is believed to be caused by transmission of mad cow disease (bovine spongiform encephalopathy or BSE) to humans. ${ }^{160-162}$ By l October 2001, 109 cases had been identified-two in France and 107 in the United Kingdom. ${ }^{163}{ }^{164}$ Variant Creutzfeldt-Jakob disease is distinctly different from SCJD in its clinical presentation and pathology. Clinically it presents as a neuropsychiatric disorder and tends to affect much younger patients, typically young adults and teenagers, with an average age of 29 years. ${ }^{162}$ The youngest patient so far was 12 years old and the oldest $74 .{ }^{165} 166$

Diagnostic criteria for the VCJD have been divided into possible, probable, and definite cases. Probable cases require a progressive psychiatric disorder of at least six months' duration without a history of iatrogenic exposure, an EEG not consistent with SCJD, an MRI consistent with the diagnosis, and at least four of the following five clinical symptoms: early psychiatric symptoms, persistent painful or unpleasant dysaesthesias, ataxia, dementia, and a movement disorder (chorea, myoclonus, or dystonia). Possible vCJD includes all criteria for probable vCJD, except they do not have an MRI suggestive of vCJD. Definite vCJD requires pathological confirmation (brain or tonsillar tissue). ${ }^{162} 164$

Median survival is much longer than in SCJD, at about 14.5 months. ${ }^{162}$ On neuropathology, there is often vacuolation, diffuse astrogliosis, and numerous "kuru-type" florid plaques (resembling those found in patients with kuru), which contain a PrP positive staining core surrounded by vacuolar (spongiform) change.

Brain biopsy or necropsy has been the standard for the definitive pathological diagnosis of human prion diseases. However, tonsil biopsy specimens have been shown to be positive for prion protein $\left(\mathrm{PrP}^{\mathrm{sc}}\right)$ by immunohistochemistry and western blot in VCJD, but not in SCJD; this should result in an easier and less invasive method of making a definitive diagnosis of vCJD. ${ }^{167}$ Proton density, T2, FLAIR, and DWI on MRI 
show bilaterally high signals in the pulvinar, giving the so called "pulvinar sign", or in the dorsomedial thalamic nuclei, or both, giving the "double hockey stick" sign. Symmetrical high signal changes are also often seen in the striatum. ${ }^{168}{ }^{169} \mathrm{~A}$ report by Oppenheim et al that noted a symmetrically high signal on various MRI sequences also identified a true diffusion abnormality in the striatum (not a T2 weighted shine-through effect), but not in the pulvinar. ${ }^{163} 168$ Whether this diffusion abnormality will be found in other vCJD cases has yet to be determined.

Kuru was a disease of the Fore (pronounced Foray) people in Papua New Guinea; kuru means "to shake or tremble" in the Fore language. The tribe's former practice of ritualistic cannibalism resulted in human to human transmission of prions. Symptoms include loss of coordination, decreased ability to walk progressing to complete inability, dementia, and death-usually within nine months. ${ }^{144}{ }^{170}$ As kuru is essentially an extinct disease it will not be discussed further.

Gerstmann-Sträussler-Scheinker syndrome is a rare familial variant of Creutzfeldt-Jakob disease characterised by spinocerebellar ataxia, diminished reflexes, and usually dementia. Amyotrophy and parkinsonian signs may appear early or late in the disease course. Myoclonus may not be present. The ataxia is often the presenting sign and can occur at an early age, often in the third to fourth decades, but up to the seventh decade. The disease runs a longer course than Creutzfeldt-Jakob disease, with death occurring in two to 10 years, with a mean of about five years. Unlike CreutzfeldtJakob disease, periodic synchronous discharges on the EEG are not seen in Gerstmann-Sträussler-Scheinker syndrome. The disease is also transmissible to primates. Occasionally it can present with a clinical syndrome that resembles conventional Creutzfeldt-Jakob disease or even typical Alzheimer's disease. ${ }^{137} 143151$

Familial fatal insomnia is an inherited form of prion disease characterised by the development of untreatable insomnia, followed by dysautonomia, ataxia, and variable pyramidal and extrapyramidal signs. Cognitive function is often spared until late in the disease course. ${ }^{144}{ }^{151} \mathrm{~A}$ rare sporadic form of Creutzfeldt-Jakob disease can mimic the signs and symptoms of fatal familial insomnia. ${ }^{145}$

Treatment strategies for Creutzfeldt-Jakob disease will probably interrupt the process in which a nascent $\mathrm{PrP}^{\mathrm{Sc}}$ directs the refolding of $\operatorname{PrP}^{\mathrm{C}}$ into a nascent $\mathrm{PrP}^{\mathrm{sc}}$, or promote clearing of $\mathrm{PrP}^{\mathrm{sc}}$ from cells. ${ }^{171}$ Evidence suggests that a third as yet undiscovered protein is needed for the templating process that causes the conformational change of $\mathrm{PrP}^{\mathrm{C}}$ into a nascent $\operatorname{PrP}^{\mathrm{Sc}} \cdot{ }^{137}{ }^{144}$ This third protein may also be a target for treatment. Prion diseases are less diseases of accumulation of abnormal proteins than disorders of protein conformation. The recent completion of the human genome project suggests that human complexity and diversity are not so much a result of the complexity of the human genome but more of the intricacy of protein expression and conformation. Studying diseases in which conformational changes in proteins play a central role in pathogenesis will probably help in further elucidating the basis of other human diseases. Prion diseases remain untreatable and invariably fatal, but it is of paramount importance that treatable conditions mimicking prion disease be excluded in patients with rapidly progressive dementia.

\section{CONCLUSIONS}

The four most common presenile neurodegenerative dementias have various features in common. The prominent role of protein aggregates in the pathology of Alzheimer's disease, frontotemporal dementia, dementia with Lewy bodies, and Creutzfeldt-Jakob disease is the most striking similarity. Treatment strategies for Alzheimer's disease are focusing on preventing the development or speeding up the clearance of these aggregates. As more is learned about protein aggregation and its downstream effects leading to cell injury and death, one hopes that future treatment strategies will take advantage of any pathogenic overlap and therefore be more broadly applicable across these devastating disorders. At a minimum, one can expect that effective treatments in one of these disorders should guide and facilitate the development of treatment in the others.

The focal brain regions where these proteins accumulate and kill neurones are different for Alzheimer's disease, frontotemporal dementia, DLB, and Creutzfeldt-Jakob disease, and this anatomical variability leads to distinctive clinical syndromes that can be diagnosed during life. ${ }^{63}$ Once the type of dementia is determined, treatment can be initiated based upon the distinctive neurotransmitter deficits associated with each disease. However, neurotransmitter modifying agents only treat symptoms and do little to slow down, and nothing to prevent, the disorder. Yet vigorous efforts are under way to develop treatments that modify the basic causes for Alzheimer's disease, frontotemporal dementia, DLB, and Creutzfeldt-Jakob disease; effective therapeutic approaches to these conditions will require an understanding of their molecular basis. Similarly, for issues related to nomenclature, a mechanism based approach will some day supplement a syndrome based system. However, changing the names for diseases is a slow and inherently conservative process.

\section{ACKNOWLEDGEMENTS}

We would like to thank Drs Howard Rosen, Patrick Bosque, and Maria Luisa Gorno Tempini, and Mrs Jill Goldman for critical review and contribution to this manuscript. In addition, we would like to thank Ms Sangeeta Bhojwani for her excellent technical assistance. Grant sponsors were the National Institutes of Health, grant number MH19938; the Kendall fund; the Sinclair fund; and the Bettye Ferguson fellowship.

\section{Authors' affiliations}

M D Greicius, Department of Psychiatry and Behavioral Sciences, Stanford University School of Medicine, Stanford, California, USA M D Geschwind, B L Miller, Department of Neurology, UCSF School of Medicine, San Francisco, California, USA

\section{REFERENCES}

Blessed G, Tomlinson BE, Roth $M$. The association between quantitative measures of dementia and of senile change in the cerebral grey matter of elderly subjects. Br J Psychiatry 1968;1 14:797-811.

2 Prusiner SB. Molecular biology of prion diseases. Science 1991;252:1515-22.

3 Berrios GE. The history of mental symptoms: descriptive psychopathology since the nineteenth century. Cambridge: Cambridge University Press, 1996

4 Brun A, Englund B, Gustafson L, et al. Clinical and neuropathological criteria for frontotemporal dementia. J Neurol Neurosurg Psychiatry 1994;57:416-18.

5 Selkoe DJ. The molecular pathology of Alzheimer's disease. Neuron $1991 ; 6: 487-98$

6 Hong M, Zhukareva V, Vogelsberg-Regaglia V. Mutation-specific functional impairments in distinct tau isoforms of hereditary FTDP-17. Science 1998;282:1914-17.

7 Hutton M, Lendon CL, Rizzu P, et al. Association of missense and $5 \mathrm{~N}$-splice-site mutations in tau with the inherited dementia FTDPB 17. Nature 1998;393:702-5

8 Goedert M, Crowther RA, Spillantini MG. Tau mutations cause frontotemporal dementias. Neuron 1998;21:955-8.

9 Spillantini M, Schmidt M, Lee V. Alpha-synuclein in Lewy bodies. Nature 1997;388:839-40.

10 Roses AD. Apolipoprotein E affects the rate of Alzheimer disease expression: beta-amyloid burden is a secondary consequence dependent on APOE genotype and duration of disease [see comments]. J Neuropathol Exp Neurol 1994;53:429-37.

11 Galasko D, Saitoh T, Xia Y. The apolipoprotein E allele epsilon 4 is overrepresented in patients with the Lewy body variant of Alzheimer's disease. Neurology 1994:44:1950-1.

12 Lippa CF, Smith TW, Saunders AM, et al. Apolipoprotein E genotype and Lewy body disease. Neurology 1995;45:97-103. 
13 Parchi P, Giese A, Capellari S, et al. Classification of sporadic Creutzfeldt-Jakob disease based on molecular and phenotypic analysis of 300 subjects. Ann Neurol 1999;46:224-33

14 Kertesz A. Frontotemporal dementia, Pick disease, and corticobasal degeneration. Arch Neurol 1997:54:1427-9.

15 Bugiani O, Murrell J, Giaccone G, et al. Frontotemporal dementia and corticobasal degeneration in a family with a P301S mutation in tau. J Neuropathol Exp Neurol 1999;58:667-77.

16 Hendrie HC. Epidemiology of dementia and Alzheimer's disease. Am J Geriatr Psychiatry 1998;6(suppl 1):S3-18.

17 Plassman BL, Breitner JC. Recent advances in the genetics of Alzheimer's disease and vascular dementia with an emphasis on gene-environment interactions. J Am Geriatr Soc 1996;44:1242-50.

18 Ropper AH, Williams RS. Relationship between plaques, tangles, and dementia in Down syndrome. Neurology 1980;30:639-44.

19 St George-Hyslop P, Tanzi R, Polinsky R, et al. The genetic defect causing familial Alzheimer's disease maps on chromosome 21. Science 1987;235:885-90.

20 Goate A, Chartier-Harlin M, Mullan M. Segregation of a missense mutation in the amyloid precursor protein gene with familial Alzheimer's disease. Nature 1991;349:704-6.

21 Schellenberg GD. Genetic dissection of Alzheimer disease, a heterogeneous disorder. Proc Natl Acad Sci USA 1995;92:8552-9.

22 Rogaev E, Sherrington R, Liang Y. Familial Alzheimer's disease in kindreds with missense mutations in a gene on chromosome 1 related to the Alzheimer's disease type 3 gene. Nature 1995;376:600-2.

23 Selkoe DJ. Alzheimer's disease: genotypes, phenotypes, and treatments. Science 1997:275:630-1.

24 Saunders AM, Strittmatter WJ, Schmechel D, et al. Association of apolipoprotein E allele epsilon 4 with late-onset familial and sporadic Alzheimer's disease. Neurology 1993;43:1467-72.

25 Blacker D, Wilcox MA, Laird NM, et al. Alpha-2 macroglobulin is genetically associated with Alzheimer disease. Nat Genet 1998; 19:357-60.

26 Braak H, Braak E. Staging of Alzheimer's disease-related neurofibrillary changes. Neurobiol Aging 1995;16:271-84

27 Arriagada PV, Marzloff K, Hyman BT. Distribution of Alzheimer-type pathologic changes in nondemented elderly individuals matches the pattern in Alzheimer's disease. Neurology 1992;42:1681-8

28 McKhann G, Drachman D, Folstein M, et al. Clinical diagnosis of Alzheimer's disease: report of the NINCDS-ADRDA Work Group under the auspices of Department of Health and Human Services Task Force on Alzheimer's Disease. Neurology 1984;34:939-44.

29 Kukull WA, Larson EB, Reifler BV, et al. Interrater reliability of Alzheimer's disease diagnosis. Neurology 1990;40:257-60.

30 Kazee AM, Eskin TA, Lapham LW, et al. Clinicopathologic correlates in Alzheimer disease: assessment of clinical and pathologic diagnostic criteria. Alzheimer Dis Assoc Disord 1993;7:152-64.

31 Blacker D, Albert MS, Bassett SS, et al. Reliability and validity of NINCDS-ADRDA criteria for Alzheimer's disease. The National Institute of Mental Health Genetics Initiative. Arch Neurol 1994;51:1 198-204.

32 Consensus report of the Working Group on Molecular and Biochemical Markers of Alzheimer's Disease. The Ronald and Nancy Reagan Research Institute of the Alzheimer's Association and the National Institute on Aging Working Group. Neurobiol Aging 1998; 19:109-16.

33 Mayeux R, Saunders AM, Shea S, et al. Utility of the apolipoprotein E genotype in the diagnosis of Alzheimer's disease. N Engl J Med 1998:338:506-11.

34 Fox N, Warrington EK, Seiffer AL, et al. Presymptomatic cognitive deficits in individuals at risk of familial Alzheimer's disease. Brain 1998;121:1631-9.

35 Haxby JV, Grady CL, Koss E, et al. Longitudinal study of the cerebral metabolic asymmetries and associated neuropsychological patterns in early dementia of Alzheimer type. Arch Neurol 1990:47:753-60.

36 Johnson J, Head E, Kim R, et al. Clinical and pathological evidence for a frontal variant of Alzheimer disease. Arch Neurol 1999;56:1233-9.

37 Benson DF, Davis RJ, Snyder BD. Posterior cortical atrophy. Arch Neurol 1988:45:789-93

38 Kramer J, Miller B. Alzheimer's disease and its focal variants. Semin Neurol 2000;20:447-54

39 Cummings JL, Miller B, Hill MA, et al. Neuropsychiatric aspects of multi-infarct dementia and dementia of the Alzheimer type. Arch Neurol 1987;44:389-93.

40 Molsa PK, Marttila RJ, Rinne UK. Survival and cause of death in Alzheimer's disease and multi-infarct dementia. Acta Neurol Scand 1986;74:103-7

41 Walsh JS, Welch HG, Larson EB. Survival of outpatients with Alzheimer-type dementia. Ann Intern Med 1990;1 13:429-34.

42 Johnson K, Albert MS. Perfusion abnormalities in prodromal AD. Neurobiol Aging 2000;21:289-92.

43 Frisoni GB, Laakso MP, Beltramello A, et al. Hippocampal and entorhinal cortex atrophy in frontotemporal dementia and Alzheimer's disease. Neurology 1999;52:91-100.

44 Detoledo-Morrell L, Sullivan MP, Morrell F, et al. Alzheimer's disease: in vivo detection of differential vulnerability of brain regions. Neurobiol Aging 1997; 18:463-8.

45 Bookheimer SY, Strojwas MH, Cohen MS, et al. Patterns of brain activation in people at risk for Alzheimer's disease. N Engl J Med 2000;343:450-6.

46 Mentis MJ, Horwitz B, Grady CL, et al. Visual cortical dysfunction in Alzheimer's disease evaluated with a temporally graded "stress test" during PET. Am J Psychiatry 1996;153:32-40.
47 Petersen RC, Smith GE, Waring SC, et al. Mild cognitive impairment: clinical characterization and outcome. Arch Neurol 1999;56:303-8. 48 Mayeux R, Sano M. Drug therapy: treatment of Alzheimer's disease. N Engl J Med 1999;341:1670-9.

49 Rogers SL, Farlow MR, Doody RS, et al. A 24-week, double-blind placebo-controlled trial of donepezil in patients with Alzheimer's disease. Neurology 1998;50: 136-45.

50 Burns A, Rossor M, Hecker J. The effects of donepezil in Alzheimer's disease - results from a multinational trial. Dement Geriatr Cogn Disord $1999 ; 10: 237-44$

51 Doody R, Geldmacher D, Gordon B, et al. Open-label, multicenter, phase 3 extension study of the safety and efficacy of donepezil in patients with Alzheimer disease. Arch Neurol 2001;58:427-33.

52 Sano M, Ernesto C, Thomas RG, et al. A controlled trial of selegiline, alpha-tocopherol, or both as treatment for Alzheimer's disease. The Alzheimer's Disease Cooperative Study. N Engl J Med 1997;336:1216-22.

53 Jeste DV, Rockwell E, Harris M, et al. Conventional vs. newer antipsychotics in elderly patients. Am J Geriatr Psychiatry 1999;7:70-6.

54 Raskind MA. Evaluation and management of aggressive behavior in the elderly demented patient. J Clin Psychiatry 1999;60(suppl 15):45-9.

55 McShane R, Keene J, Gedling K, et al. Do neuroleptic drugs hasten cognitive decline in dementia? Prospective study with necropsy follow-up. BMN 1997:314:266-70.

56 Koiro E, Gimpl G, Lammich S, et al. Low cholesterol stimulates the nonamyloidogenic pathway by its effect on the alpha-secretase ADAM 10. Proc Natl Acad Sci USA 2001;17:17.

57 Dovey HF, John V, Anderson JP, et al. Functional gamma-secretase inhibitors reduce beta-amyloid peptide levels in brain. J Neurochem 2001;76:173-81.

58 Schenk D, Barbour R, Dunn W, et al. Immunization with amyloid-beta attenuates Alzheimer-disease-like pathology in the PDAPP mouse [see comments]. Nature 1999:400:173-7.

59 Raber J, Wong $D$, Buttini $M$, et al. Isoform-specific effects of human apolipoprotein $\mathrm{E}$ on brain function revealed in ApoE knockout mice: increased susceptibility of females. Proc Natl Acad Sci USA 1998;95:10914-19.

60 Nestor $\mathbf{P}$, Hodges J. Non-Alzheimer dementias. Semin Neurol 2000;20:439-46.

61 Hodges JR, Miller B. The classification, genetics and neuropathology of frontotemporal dementia. Introduction to the special topic papers. Part I. Neurocase 2001;7:31-5.

62 Neary D, Snowden JS, Shields RA, et al. Single photon emission tomography using $99 \mathrm{mTc}-\mathrm{HM}-\mathrm{PAO}$ in the investigation of dementia. $J$ Neurol Neurosurg Psychiatry 1987; 50:1101-9

63 Brun A. Frontal lobe degeneration of non-Alzheimer type. I. Neuropathology. Arch Gerontol Geriatr 1987;6:193-208.

64 Clark LN, Poorkaj P, Wszolek Z, et al. Pathogenic implications of mutations in the tau gene in pallido-ponto-nigral degeneration and related neurodegenerative disorders linked to chromosome 17. Proc Nat Acad Sci USA 1998;95:13103-7.

65 Miller BL, Boone K, Mishkin F, et al. Clinical and neuropyschological features of frontotemporal dementia. In: Kertesz A, et al, eds. Pick's disease and Pick complex. New York: Wiley-Liss, 1998:23-32.

66 Neary D, Snowden JS, Northen B, et al. Dementia of frontal lobe type. J Neurol Neurosurg Psychiatry 1988;51:353-61

67 Snowden JS, Neary D, Mann DMA. The differential diagnosis of frontotemporal dementia. In: Fronto-temporal lobar degeneration: fronto-temporal dementia, progressive aphasia, semantic dementia. New York: Churchill Livingstone, 1996:43-58

68 Neary D, Snowden JS, Gustafson L, et al. Frontotemporal lobar degeneration: a consensus on clinical diagnostic criteria. Neurology 1998;51:1546-54

69 Wilhelmsen KC, Lynch T, Pavlou E, et al. Localization of disinhibition-dementia-parkinsonism-amyotrophy complex to 17q21-22. Am J Hum Genet 1994;55: 1159-65.

70 Wilhelmsen KC, Clark LN, Miller BL, et al. Tau mutations in frontotemporal dementia. Dement Geriatr Cogn Disord 1999;10/suppl 1):880-2.

71 Gustafson L. Frontal lobe degeneration of non-Alzheimer type. II. Clinical picture and differential diagnosis. Arch Gerontol Geriatr 1987;6:209-23

72 Chow TW, Miller BL, Hayashi VN, et al. Inheritance of frontotemporal dementia. Arch Neurol 1999;56:817-22.

73 Heutink P. Untangling tau-related dementia. Hum Mol Genet 2000;9:979-86.

74 Zhukareva V, Vogelsberg-Ragaglia V, Van Deerlin VM, et al. Loss of brain tau defines novel sporadic and familial tauopathies with frontotemporal dementia. Ann Neurol 2001;49:165-75.

75 Houlden $\mathbf{H}$, Baker $M$, Adamson J, et al. Frequency of tau mutations in three series of non-Alzheimer's degenerative dementia. Ann Neurol 1999:46:243-8

76 Rizzu P, Van Swieten JC, Joosse M, et al. High prevalence of mutations in the microtubule-associated protein tau in a population study of frontotemporal dementia in the Netherlands. Am J Hum Genet 1999:64:414-21.

77 Brown J, Ashworth A, Gydesen S, et al. Familial non-specific dementia maps to chromosome 3. Hum Mol Genet 1995;4:1625-8.

78 Hosler BA, Siddique T, Sapp PC, et al. Linkage of familial amyotrophic lateral sclerosis with frontotemporal dementia to chromosome 9q21-q22. JAMA 2000;284: 1664-9.

79 Brun A. Frontal lobe degeneration of non-Alzheimer type revisited. Dementia 1993;4:126-31. 
80 Nasreddine ZS, Loginov M, Clark LN, et al. From genotype to phenotype: a clinical pathological, and biochemical investigation of frontotemporal dementia and parkinsonism (FTDP-17) caused by the P301L tau mutation. Ann Neurol 1999;45:704-15.

81 Delacourte A. Biochemical and molecular characterization of neurofibrillary degeneration in frontotemporal dementias. Dement Geriatr Cogn Disord 1999;10(suppl 1):75-9.

82 Kertesz A, Kawarai T, Rogaeva E, et al. Familial frontotemporal dementia with ubiquitin-positive, tau-negative inclusions. Neurology 2000;54:818-27.

83 Kertesz A, Martinez-Lage P, Davidson W, et al. The corticobasal degeneration syndrome overlaps progressive aphasia and frontotemporal dementia. Neurology 2000;55:1368-75

84 Gearing $M$, Olson DA, Watts RL, et al. Progressive supranuclear palsy: neuropathologic and clinical heterogeneity. Neurology 1994:44:1015-24

85 Esmonde T, Giles E, Gibson M, et al. Neuropsychological performance, disease severity, and depression in progressive supranuclear palsy. J Neurol 1996;243:638-43

86 Mathuranath PS, Xuereb JH, Bak T, et al. Corticobasal ganglionic degeneration and/or frontotemporal dementia? A report of two overlap cases and review of literature. $J$ Neurol Neurosurg Psychiatry 2000:68:304-12.

87 Grimes DA, Lang AE, Bergeron CB. Dementia as the most common presentation of cortical-basal ganglionic degeneration. Neurology 1999;53:1969-74.

88 Houlden H, Baker $M$, Morris HR, et al. Corticobasal degeneration and progressive supranuclear palsy share a common tau haplotype. Neurology 2001;56:1702-6.

89 Feany MB, Dickson DW. Neurodegenerative disorders with extensive tau pathology: a comparative study and review. Ann Neurol 1996;40:139-48.

90 Di Maria E, Tabaton M, Vigo T, et al. Corticobasal degeneration shares a common genetic background with progressive supranuclear palsy. Ann Neurol 2000;47:374-7.

91 van Slegtenhorst $M$, Lewis J, Hutton $M$. The molecular genetics of the tauopathies. Exp Gerontol 2000;35:461-71.

92 Miller BL, Chang L, Mena I, et al. Progressive right frontotemporal degeneration: clinical, neuropsychological and SPECT characteristics. Dementia 1993:4:204-13.

93 Edwards-Lee T, Miller BL, Benson DF, et al. The temporal variant of frontotemporal dementia. Brain 1997;1 20:1027-40.

94 Rosen HJ, Lengenfelder J, Miller B. Frontotemporal dementia. Neurol Clin 2000; 18:979-92.

95 Mesulam MM. Slowly progressive aphasia without generalized dementia. Ann Neurol 1982;11:592-8.

96 Snowden JS, Goulding PJ, Neary D. Semantic dementia: a form of circumscribed cerebral atrophy. Behav Neurol 1989;2:167-82.

97 Hodges JR, Patterson K, Oxbury S, et al. Semantic dementia. Progressive fluent aphasia with temporal lobe atrophy. Brain 1992; 115: 1783-806.

98 Rossor MN. Differential diagnosis of frontotemporal dementia: Pick's disease. Dement Geriatr Cogn Disord 1999;10(suppl 1):43-5.

99 Miller BL, Ikonte C, Ponton M, et al. A study of the Lund-Manchester research criteria for frontotemporal dementia: clinical and single-photon emission CT correlations. Neurology 1997;48:937-42.

100 Lopez OL, Litvan I, Catt KE, et al. Accuracy of four clinical diagnostic criteria for the diagnosis of neurodegenerative dementias. Neurology 1999:53:1292-9.

101 Miller BL, Gearhart R. Neuroimaging in the diagnosis of frontotempora dementia. Dement Geriatr Cogn Disord 1999;10(suppl 1):71-4.

102 Swartz JR, Miller BL, Lesser IM, et al. Frontotemporal dementia: treatment response to serotonin selective reuptake inhibitors [published erratum appears in J Clin Psychiatry 1997 Jun;58(6):275]. J Clin Psychiatry 1997;58:212-16.

103 Sparks DL, Woeltz VM, Markesbery WR. Alterations in brain monoamine oxidase activity in aging, Alzheimer's disease, and Pick's disease. Arch Neurol 1991;48:718-21.

104 Francis $\mathbf{P}$, Holmes $C$, Webster $M$, et al. Preliminary neurochemical findings in non-Alzheimer dementia due to lobar atrophy. Dementia 1993;4:172-7.

105 Perry RJ, Miller BL. Behavior and treatment in frontotemporal dementia. Neurology 2001;56(suppl 4):S46-51.

106 McKeith IG, Galasko D, Kosaka K, et al. Consensus guidelines for the clinical and pathologic diagnosis of dementia with Lewy bodies (DLB): report of the consortium on DLB international workshop. Neurology 1996;47: $1113-24$

107 Papka M, Rubio A, Schiffer R. A review of Lewy body disease, an emerging concept of cortical dementia. J Neuropsychiatry Clin Neurosci 1998;10:267-79.

108 Perry RH, Irving D, Blessed G, et al. Clinically and neuropathologically distinct form of dementia in the elderly. Lancet 1989;i:166.

109 Ince PG, McArthur FK, Bjertness E, et al. Neuropathological diagnoses in elderly patients in Oslo: Alzheimer's disease, Lewy body disease, vascular lesions. Dementia 1995;6:162-8.

110 Kosaka K, Iseki E. Diffuse Lewy body disease within the spectrum of Lewy body disease. Proceedings of International Workshop on Lewy Body Dementia. Pathology 1995;27:1-13.

111 Weiner MF, Risser RC, Cullum CM, et al. Alzheimer's disease and its Lewy body variant: a clinical analysis of postmortem verified cases. Am Psychiatry 1996;153:1269-73.

112 Polymeropoulos $\mathbf{M H}$, Lavedan C, Leroy E, et al. Mutation in the alpha-synuclein gene identified in families with Parkinson's disease. Science 1997;276:2045-47.
113 Farrer M, Gwinn-Hardy K, Hutton M, et al. The genetics of disorders with synuclein pathology and parkinsonism. Hum Mol Genet 1999;8: 1901-5.

114 Muenter MD, Forno LS, Hornykiewicz O, et al. Hereditary form of parkinsonism-dementia. Ann Neurol 1998;43:768-81.

115 Chen L, Baum L, Ng HK, et al. Apolipoprotein E promoter and alpha2-macroglobulin polymorphisms are not genetically associated with Chinese late-onset Alzheimer's disease. Neurosci Lett 1999;269:173-7.

116 Filley C. Neuropsychiatric features of Lewy body disease. Brain Cogn 1995;28:229-39.

117 McKeith IG, Perry EK, Perry RH. Report of the second dementia with Lewy body international workshop: diagnosis and treatment. Consortium on Dementia with Lewy Bodies. Neurology 1999;53:902-5.

118 Dickson DW, Schmidt ML, Lee VM, et al. Immunoreactivity profile of hippocampal CA2/3 neurites in diffuse Lewy body disease. Acta Neuropathol 1994;87:269-76.

119 Jensen $\mathbf{P}$, Nielsen $M$, Jakes R, et al. Binding of alpha-synuclein to brain vesicles is abolished by familial Parkinson's disease mutation. J Biol Chem 1998;273:26292-4.

120 Wolozin B, Behl C. Mechanisms of neurodegenerative disorders. Part 1 Protein aggregates. Arch Neurol 2000;57:793-6.

121 Conway K, Harper J, Lansbury P. Accelerated in vitro fibril formation by a mutant alpha-synuclein linked to early-onset Parkinson disease. Nat Med 1998;4:1318-20.

122 Hashimoto $M, H_{s u} L$, Xia $Y$, et al. Oxidative stress induces amyloid-like aggregate formation of NACP/alpha-synuclein in vitro. Neuroreport 1999;10:717-21.

123 Duda JE, Lee VM, Trojanowski JQ. Neuropathology of synuclein aggregates. J Neurosci Res 2000;61:121-7.

124 Mega MS, Masterman DL, Benson DF, et al. Dementia with Lewy bodies: reliability and validity of clinical and pathologic criteria. Neurology 1996;47: 1403-9.

125 Holmes C, Cairns N, Lantos P, et al. Validity of current clinical criteria for Alzheimer's disease, vascular dementia, and dementia with Lewy bodies. Br J Psychiatry 1999;174:45-51

126 McKeith I, Fairbairn A, Perry R, et al. Neuroleptic sensitivity in patients with senile dementia of Lewy body type. BM 1992;305:673-8.

127 Barber R, Ballard C, McKeith IG, et al. MRI volumetric study of dementia with Lewy bodies: a comparison with $A D$ and vascular dementia. Neurology 2000;54:1304-9.

128 Hashimoto $\mathbf{M}$, Kitagaki H, Imamura T. Medial temporal and whole-brain atrophy in dementia with Lewy bodies, a volumetric MRI study. Neurology 1998;51:357-62.

129 Perry RH, Irving D, Blessed G, et al. Senile dementia of Lewy body type. A clinically and neuropathologically distinct form of Lewy body dementia in the elderly. J Neurol Sci 1990;95:119-39.

130 Lanctot K, Herrmann N. Donepezil for behavioral disorders associated with Lewy bodies: a case series. Int J Geriatr Psychiatry 2000; 15:338-45

131 Shea C, MacKnight C, Rockwood K. Donepezil for treatment of Lewy bodies: a case series of nine patients. Int Psychogeriatr 1998; 10:229-38.

132 McKeith I, Del Ser T, Spano P, et al. Efficacy of rivastigmine in dementia with Lewy bodies: a randomised, double-blind, placebo-controlled international study. Lancet 2000;356:2031-6.

133 McKeith I, Ballard C, Harrison R. Neuroleptic sensitivity to risperidone in Lewy body dementia [letter]. Lancet 1995;346:699.

134 Walker Z, Grace J, Overshot R, et al. Olanzapine in dementia with Lewy bodies: a clinical study. Int J Geriatr Psychiatry 1999;14:459-66.

135 Burke W, Pfeiffer R, McComb R. Neuroleptic sensitivity to clozapine in dementia with Lewy bodies. J Neuropsychiatry Clin Neurosci 1998;10:227-9.

136 Prusiner SB. Novel proteinaceous infectious particles cause scrapie. Science 1982;216:136-44

137 Prusiner SB. Prions. Proc Natl Acad Sci USA 1998;95:13363-83.

138 Will RG, Alpers MP, Dormont D, et al. Infectious and sporadic prion diseases. In: Prusiner SB, ed. Prion biology and diseases. Cold Spring Harbor: Cold Spring Harbor Laboratory Press, 1999:465-507.

139 Prusiner SB. Genetic and infectious prion diseases. Arch Neurol 1993;50: 1129-53

140 Brown P, Cathala F, Castaigne P, et al. Creutzfeldt-Jakob disease: clinical analysis of a consecutive series of 230 neuropathologically verified cases. Ann Neurol 1986;20:597-602.

141 Brown P, Gibbs CJ, Rodgers-Johnson P, et al. Human spongiform encephalopathy: the National Institutes of Health series of 300 cases of experimentally transmitted disease. Ann Neurol 1994;35:513-29.

142 Gambetti P, Parchi P. Insomnia in prion diseases: sporadic and familial. N Engl J Med 1999;340:1675-7.

143 Gambetti P, Petersen RB, Parchi P, et al. Inherited prion diseases. In: Prusiner SB, ed. Prion biology and diseases. Cold Spring Harbor: Cold Spring Harbor Laboratory Press, 1999:508-83.

144 Prusiner SB, Bosque PJ. Prion diseases. In: Braunwald E, ed. Harrison's Principles of internal medicine. New York: McGraw Hill, 2001.

145 Mastrianni JA, Roos RP. The prion diseases. Semin Neurol 2000;20:337-52

146 Kretzschmar HA, Ironside JW, DeArmond SJ, et al. Diagnostic criteria for sporadic Creutzfeldt-Jakob disease. Arch Neurol 1996;53:913-20.

147 Guentchev M, Wanschitz J, Voigtlander T, et al. Selective neuronal vulnerability in human prion diseases. Fatal familial insomnia differs from other types of prion diseases. Am J Pathol 1999;155:1453-7.

148 Ferrer I, Casas R, Rivera R. Parvalbumin-immunoreactive cortical neurons in Creutzfeldt-Jakob disease. Ann Neurol 1993;34:864-6. 
149 Guentchev M, Groschup MH, Kordek R, et al. Severe, early and selective loss of a subpopulation of GABAergic inhibitory neurons in experimental transmissible spongiform encephalopathies. Brain Pathol 1998;8:615-23

150 Belichenko PV, Miklossy J, Belser B, et al. Early destruction of the extracellular matrix around parvalbumin-immunoreactive interneurons in Creutzfeldt-Jakob disease. Neurobiol Dis 1999;6:269-79.

151 Belay ED. Transmissible spongiform encephalopathies in humans. Annu Rev Microbiol 1999;53:283-314.

152 Cummings JL, Benson DF. Dementia in vascular and infectious disorders. In: Dementia: a clinical approach. Boston: Butterworth, 1983:125-67.

153 Masters CL, Gajdusek DC, Gibbs CJ. The familial occurrence of Creutzfeldt-Jakob disease and Alzheimer's disease. Brain 1981;104:535-58

154 Will RG, Alperovitch A, Poser S, et al. Descriptive epidemiology of Creutzfeldt-Jakob disease in six European countries, 1993-1995. EU Collaborative Study Group for CJD. Ann Neurol 1998;43:763-7.

155 Pals $\mathbf{P}$, Van Everbroeck B, Sciot R, et al. A retrospective study of Creutzfeldt-Jakob disease in Belgium. Eur J Epidemiol 1999;15:517-19.

156 Vrancken AF, Frijns CJ, Ramos LM. FLAIR MRI in sporadic Creutzfeldt-Jakob disease. Neurology 2000;55:147-8.

157 Collie DA, Sellar RJ, Zeidler M, et al. MRI of Creuztfeldt-Jakob disease: imaging features and recommended MRI protocol. Clin Radiol 2001;56:726-39.

158 Matoba M, Tonami H, Miyaii $\mathrm{H}$, et al. Creutzfeldt-Jakob disease: serial changes on diffusion-weighted MRI. J Comput Assist Tomogr 2001;25:274-7.
159 Poon MA, Stuckey S, Storey E. MRI evidence of cerebellar and hippocampal involvement in Creutzfeldt-Jakob disease. Neuroradiology 2001;43:746-9

160 Scott MR, Will R, Ironside J, et al. Compelling transgenetic evidence for transmission of bovine spongiform encephalopathy prions to humans. Proc Natl Acad Sci USA 1999:96:15137-42.

161 Will RG, Ironside JW, Zeidler $M$, et al. A new variant of Creutzfeldt-Jakob disease in the UK. Lancet 1996;347:921-5.

162 Will RG, Zeidler M, Stewart GE, et al. Diagnosis of new variant Creutzfeldt-Jakob disease. Ann Neurol 2000;47:575-82.

163 Oppenheim C, Brandel JP, Hauw JJ, et al. MRI and the second French case of vCJD. Lancet 2000;356:253-4.

164 Department of Health. Monthly Creutzfeldt-Jakob disease statistics. In Available: www.doh.gov.uk/cjd/cjd_stat.htm. London, 2001.

165 Verity CM, Nicoll A, Will RG et al. Variant Creutzfeldt-Jakob disease in UK children: a national surveillance study. Lancet 2000;356:1224-7.

166 Lorains JW, Henry C, Agbamu DA, et al. Variant Creutzfeldt-Jakob disease in an elderly patient. Lancet 2001;357:1339-40

167 Hill AF, Butterworth RJ, Joiner S, et al. Investigation of variant Creutzfeldt-Jakob disease and other human prion diseases with tonsil biopsy samples. Lancet 1999:353:183-9.

168 Zeidler M, Sellar RJ, Collie DA, et al. The pulvinar sign on magnetic resonance imaging in variant Creutzfeldt-Jakob disease. Lance 2000;355:1412-18

169 Zeidler M, Collie DA, Macleod MA, et al. FLAIR MRI in sporadic Creutzfeldt-Jakob disease. Neurology 2001;56:282.

170 Gajdusek DC. Unconventional viruses and the origin and disappearance of kuru. Science 1977:197:943-60.

171 Korth C, May BCH, Cohen FE, et al. Acridine and phenothiazine derivatives as pharmacoptherapeutics for prion disease. Proc Natl Acad Sci USA 2001;98:9836-41.

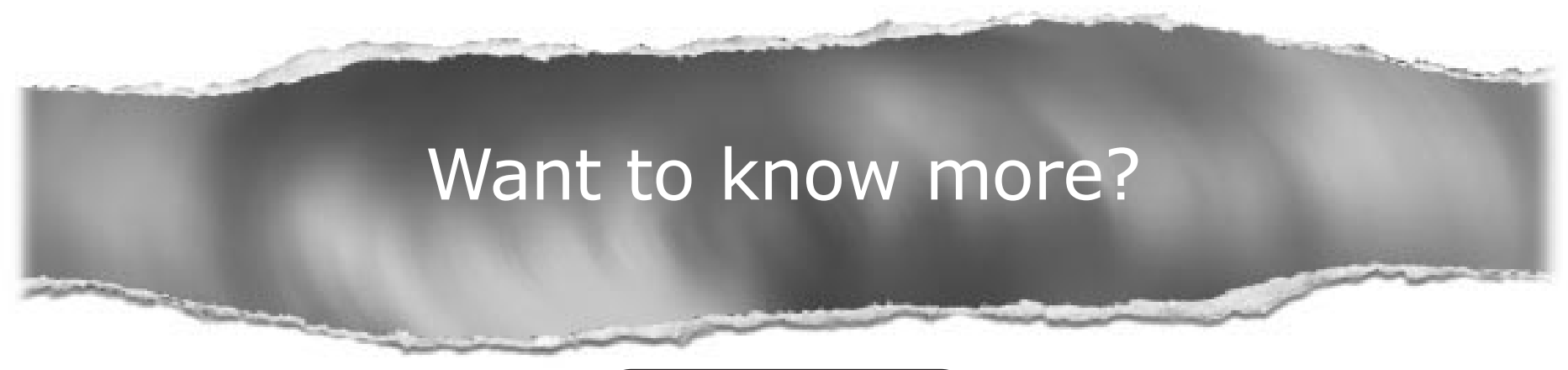

Data supplements

Limited space in printed journals means that interesting data and other material are often edited out of articles; however, limitless cyberspace means that we can include this information online.

Look out for additional tables, references, illustrations.

\section{www.jnnp.com}

